\title{
Early vesico-amniotic shunting - does it change the prognosis in fetal lower urinary tract obstruction diagnosed in the first trimester?
}

\author{
Marzena Dębska ${ }^{1}$, Piotr Kretowicz ${ }^{1}$, Anna Olędzka ${ }^{1}$, Piotr Gastoł², Joanna Dangel ${ }^{3}$, \\ Małgorzata Świątkowska-Freund ${ }^{4}$, Romuald Dębski ${ }^{1}$ \\ ${ }^{1} 2^{\text {nd }}$ Department of Obstetrics and Gynecology, The Medical Center of Postgraduate Education, Warsaw, Poland \\ ${ }^{2}$ Department of Pediatric Urology, The Children's Memorial Health Institute, Warsaw, Poland \\ ${ }^{3}$ Reference Center for Prenatal Cardiology, $2^{\text {nd }}$ Department of Obstetrics and Gynecology, Medical University of Warsaw, Poland \\ ${ }^{4}$ Department of Obstetrics, Medical University of Gdansk, Poland
}

\begin{abstract}
Objectives: The aim of the study was to assess the outcome of vesico-amniotic shunting performed before 16 weeks of pregnancy in fetuses with severe megacystis diagnosed in the first trimester of pregnancy.

Material and methods: Between January 2008 and October 2012 severe megacystis with the bladder length > 15 mm was diagnosed in 17 fetuses. The procedure of early vesico-amniotic shunting (VAS) was offered to 8 patients with presumably isolated LUTO.

The procedure of VAS was performed in 6 fetuses. Before the intervention one or two procedures of vesicocentesis and urine analysis were performed.

Results: In all treated cases shunts provided urinary tract decompression. All babies were born prematurely, 2 of them died due to premaurity, 3 of them survived and have normal renal function at the age of 5-6years. In 4/5 children accompanying malformations were later diagnosed, in 1 born prematurely neonate necropsy was not performed.

Conclusions: Our results suggest that early vesico-amniotic shunting in fetal LUTO is feasible and may potentially prevent not only pulmonary hypoplasia but also renal insufficiency. However, the rationale of the procedure needs further investigation due to a high risk of long-term morbidity and co-existing malformations in children Before offering the therapy detailed counseling of the parents about the possible pros and cons of the therapy is necessary.
\end{abstract}

Key words: first trimester scan, fetal megacystis, early vesico-amniotic shunting, LUTO, renal function

Ginekologia Polska 2017; 88, 9: 486-491

\section{INTRODUCTION}

Lower urinary tract obstruction (LUTO) is a heterogeneous group of fetal urethral anomalies that eventually lead to cystic renal dysplasia, oligo- or anhydramnios and lethal pulmonary hypoplasia. LUTO, usually in form of posterior urethral valves (PUVs) or urethral atresia, is more prevalent in male than in female fetuses [1-2]. Depending on the cause and degree of urethral obstruction, LUTO may be associated with $45-100 \%$ prenatal mortality [3], and even postnatal survivors often develop end-stage chronic renal impairment [4]. Fetal LUTO can be suspected as early as at 11-14 weeks of gestation on the basis of the urinary bladder enlargement, referred to as megacystis, especially when the fetal bladder length exceeds $15 \mathrm{~mm}$ [5]. Percutaneous vesico-amniotic shunting with drainage of fetal urine to the amniotic cavity, is the most common intervention in LUTO fetuses [6] The second option is fetal cystoscopy with laser fulguration of PUVs. Although LUTO can be suspected already in the first trimester of pregnancy, both treatment procedures are usually postponed after 16 weeks due to

Corresponding author:

Anna Olędzka

$2^{\text {nd }}$ Department of Obstetrics and Gynecology

The Medical Center of Postgraduate Education, Warsaw, Poland

Full address?

e-mail:aniaoledzka@gmail.com 
technical limitations and until the definitive diagnosis is established and renal function is verified [7]. As a result of this management, many fetuses with severe LUTO present with significant impairment of renal function at the time of diagnosis which either precludes intervention or causes later renal insufficiency. This management may increase perinatal survival of poor prognosis fetuses in which renal damage already occured only by preventing pulmonary hypoplasia caused by oligo- or anhydramnios. Owing limitations of treatment of LUTO performed after 16 weeks we offered earlier intervention in some eligible cases. We present here the outcomes of 17 consecutive pregnancies complicated by early diagnosed severe megacystis. Specifically, we focused on prenatal and postnatal outcomes of fetuses with LUTO subjected to early vesicocentesis combined with percutaneous vesico-amniotic shunting before 16 weeks of gestation.

\section{MATERIAL AND METHODS}

Our series included 17 cases of severe fetal megacystis diagnosed in our department on routine ultrasound at 11-14 weeks of gestation between January 2008 and October 2012.

All fetuses with severe megacystis (fetal bladder length $>15 \mathrm{~mm}$ ) were subjected to detailed ultrasonographic and echocardiographic examination to exclude potential co-existing malformations. Chorionic villus sampling was performed in every case to reveal fetal karyotype. Isolated LUTO was suspected whenever severe megacystis without other apparent concomitant malformations was found on routine ultrasound at 11-14 weeks of gestation. Such cases were considered eligible for early intrauterine intervention. The parents were informed about potential risks and benefits of the treatment, as well as about possible long-term outcomes in their children. The treatment was commenced only when written informed consent was obtained from a pregnant woman.

The protocol of the study was approved by the Act No. 18/PB/2013 of the Local Bioethics Committee at the Medical Center of Postgraduate Education, and all pregnant women gave their written informed consent prior to any procedure.

Before the intervention one or two procedures of vesicocentesis with a 22-gauge (G) needle was performed. Urine evacuated during the procedure was subjected to analysis in order to determine actual fetal renal function. This procedure allowed also early decompression of the urinary bladder. In all fetuses megacystis recurred despite 1-2 sequential vesicocenteses.

All the procedures of vesico-amniotic shunting were performed under ultrasound guidance with local or regional anesthesia of a pregnant woman. A double pig-tail Harrison shunt (Fetal Bladder Stent Set, Cook Medical, Inc., $1.67 \mathrm{~mm}$ in diameter) was introduced to fetal bladder via a $14-G$ needle.
Double coiled end of the shunt was placed in fetal bladder whereas the single coiled end was left in amniotic cavity. In two cases due to logistic reasons the procedure of shunting was performed before fetal karyotype was obtained. The patients were informed, that if there is abnormal karyotype the pregnancy can be terminated on their request regardless of the procedure performed.

Patients subjected to vesico-amniotic shunting were monitored ultrasonographically every two weeks for potential shunt dislocation and other complications. The shunting was repeated whenever necessary. Amniotic fluid volume, fetal bladder and kidneys were also assessed.

After delivery, all survivors were examined by urologists and pediatricians. Micturating cystourethrography and postnatal cystoscopy were used to evaluate the bladder and the urethra, as well as the residual valvular tissue, when necessary. Then the infants were continuously followed-up after birth. Serum creatinine measurements were used to determine renal function. An abnormal renal function was considered whenever serum creatinine was elevated or if dialysis or renal transplantation was necessary. Autopsy was performed when fetal or neonatal death occurred.

\section{RESULTS \\ Preintervention data}

In 7/17 cases pregnancies were terminated on parental request due to trisomy $18(n=3)$, concomitant heart defect $(n=2)$ or presumed poor prognosis $(n=2)$. Another $2 / 17 \mathrm{fe-}$ tuses were miscarried spontaneously before 16 weeks.

\section{Intrauterine intervention}

Only $8 / 17$ fetuses with severe megacystis were potentially eligible for intrauterine intervention and their parents gave consent to the treatment (Fig. 1).

A single or double vesicocentesis was performed in $7 / 8$ fetuses between 12 and 14 weeks and fetal urine was subjected to analysis in 6/7 cases. Another fetus was miscarried within a week from the vesicocentesis.

The procedures of bladder shunting were finally performed in 7/17 fetuses between 14.3 and 15.6 weeks of gestation (Figs. 2, 3).

The group subjected to vesico-amniotic shunting included 6 fetuses from singleton pregnancies and one fetus from twin monochorionic monoamniotic (MCMA) pregnancy (Case no. 3). Although twin pregnancies, especially MCMA, are usually considered a relative contraindication for such invasive procedures, we performed the shunting owing parental request. No intraoperative complications were recorded in any case. As oligohydramnios is typically not observed in LUTO before 16 weeks of pregnancy, amnioinfusion was not needed to correctly insert the shunt to the amniotic cavity. Preterm premature rupture of membranes 


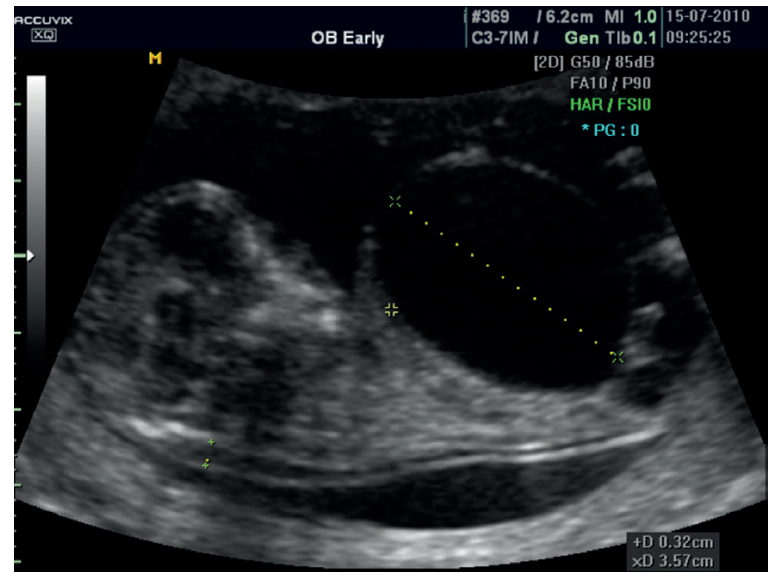

Figure 1. 13 weeks fetus with megacystis in the first trimester. Bladder length of $36 \mathrm{~mm}$ (case 1)

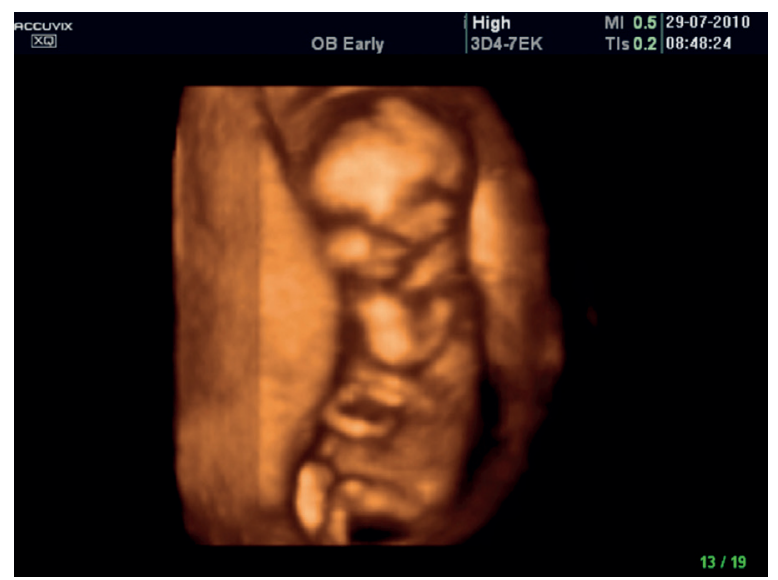

Figure 3. 15 weeks fetus after early vesico-amniotic shunting. External part of the shunt visible in front of the fetal abdomen below the fetal elbow (3D US, case 1)

(PPROM) occurred in one case (Case no. 6) within a week from the shunting. The result of genetic analysis which was available after the procedure revealed trisomy 18 and the pregnancy was terminated. Postmortem examination showed that aside from complete LUTO, the fetus presented with cleft palate.

\section{Prenatal follow-up}

All 6 treated fetuses required repeated shunting at 18.1-34.6 weeks due to shunt displacement and resultant severe oligohydramnios. The presence of oligohydramnios confirmed the diagnosis of complete LUTO. In two fetuses (Cases no. 2 and 4), amniotic end of the shunt displaced to the abdominal cavity and urinary ascites developed. In Case no. 2, the displaced shunt caused iatrogenic gastroschisis which surprisingly allowed effective drainage of the abdominal cavity. In Case no. 4 another shunt needed to be placed in the abdominal wall due to massive urinary ascites. As

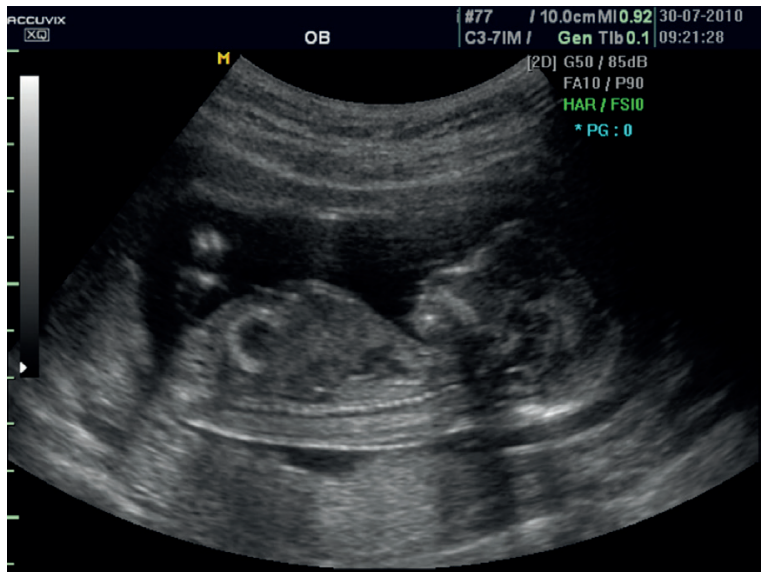

Figure 2. 15 weeks fetus after vesico-amniotic shunting. Shunt visible in fetal bladder (case 1)

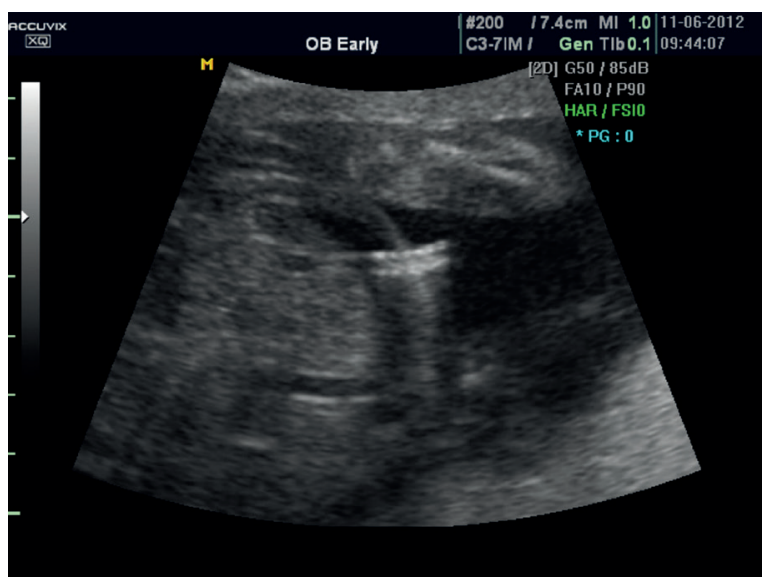

Figure 4. Coronanry stent inserted in the fetal abdominal wall

it also underwent displacement, a coronary stent (Integrity, $3.5 \times 12 \mathrm{~mm}$ ) was implanted to the abdominal wall at 21 weeks of gestation to provide a free urine outflow (Fig. 4).

Although the procedure was successful and the stent remained in place until birth, it provided drainage for no longer than 10 days and then was obstructed by fetal connective tissue. Therefore, we eventually decided on sequential abdominocenteses with subsequent amnioinfusion of fetal urine. Other anomalies were observed in later pregnancy in two fetuses - a slight unilateral hydrothorax (Case no. 5). and bowel distension and polyhydramnios in the third trimester (Case no. 3) (Table 1).

\section{Delivery and postnatal follow-up}

All six treated prenatally neonates were born prematurely. Four of them were delivered by caesarean section after 31 weeks of gestation after steroid administration to enhance lung maturity (range 31.3-34.6 weeks) and all of them survived. The indications for caesarean section 
included shunt displacement at 34.6 weeks (Case no. 1), uterine contractions after PPROM due to polyhydramnios at 31.3 weeks (Case no. 2), umbilical cord entanglement in MCMA pregnancy at 33.5 weeks (Case no. 3) and cardiotocographic evidence of fetal asphyxia at 34.5 weeks (Case no. 4). Two other babies were delivered extremely prematurely and died. One neonate (Case no. 5) was delivered spontaneously due to cervical incompetence at 25.6 weeks and died in the first day of life because of extreme prematurity. We have no data on the second neonate (Case no. 6).

Complete LUTO due to PUVs (Cases no. 1 and 3) or urethral atresia (Cases no. 2 and 4), was confirmed postnatally in all the survivors (Table 2). In Case no. 1 LUTO co-existed with right kidney hypoplasia. Two neonates (Cases no. 2 and 3) presented with right kidney hypoplasia and anal atresia. In Case no. 4 atypical diffuse bowel stricture was observed after

Table 1. Fetuses undergoing vesico-amniotic shunting prior to 16 weeks — perinatal history

\begin{tabular}{|c|c|c|c|c|}
\hline $\begin{array}{l}\text { Case } \\
\text { number }\end{array}$ & $\begin{array}{l}\text { Time of diagnosis } \\
\text { (GA in weeks / } \\
\text { /bladder length) } \\
\text { [mm] }\end{array}$ & $\begin{array}{c}\text { Shunt } \\
\text { placement } \\
\text { (GA in weeks) }\end{array}$ & $\begin{array}{l}\text { Shunt displacement/secondary shunt } \\
\text { (GA in weeks) }\end{array}$ & $\begin{array}{c}\text { Mode of delivery, indication for delivery/ } \\
\text { /(GA in weeks)/birth weight(g)/ } \\
\text { /Apgar score } \\
\text { Karyotype }\end{array}$ \\
\hline 1 & $12 / 42$ & 15.4 & $\begin{array}{c}27 \\
34.6\end{array}$ & $\begin{array}{c}\text { CS, shunt displacement } \\
34.6 \\
2640 \mathrm{~g} / 7 \\
46, \mathrm{XY}\end{array}$ \\
\hline 2 & $13.4 / 37$ & 15.5 & $\begin{array}{l}25.4 \text { abdomino-amniotic shunt, } \\
25.6 \text { shunt dislocation, } \\
\text { draining gastroschisis }\end{array}$ & $\begin{array}{c}\text { CS, PROM since } 30 \text { weeks + contractions } \\
31.3 \\
2160 \mathrm{~g} / 6 \\
46, \mathrm{XY}\end{array}$ \\
\hline $\begin{array}{c}3 \\
\text { Twins MCMA }\end{array}$ & $12 / 26$ & 15.1 & $\begin{array}{l}18.1 \text { dislocation to the amniotic cavity, } \\
\text { vesico amniotic shunt } \\
22.1 \text { dislocation to the abdomen, } \\
\text { abdomino-amniotic shunt }\end{array}$ & $\begin{array}{c}\text { CS, umbilical cord entanglement } \\
33.5 \\
\text { twin I } 2130 \mathrm{~g} \text { (with LUTO)/10/46, XY, } \\
\text { twin II } 1940 \mathrm{~g} / 10 / 46, \mathrm{XY}\end{array}$ \\
\hline 4 & $13.6 / 64$ & 14.1 & $\begin{array}{l}17.0 \text { shunt dislocation to the abdomen } \\
18.0 \text { and } 26.3 \text { abdomino-amniotic shunts } \\
21.1 \text { stent into abdominal wall } \\
\text { From } 26.6 \text { weeks }-24 \text { abdominal cavity } \\
\text { punctures }\end{array}$ & $\begin{array}{c}\text { CS, decelerations in CTG, PROM at } 33 \text { weeks } \\
34.5 \\
1950 \mathrm{~g} / 2 \\
46, \mathrm{XY}\end{array}$ \\
\hline 5 & $13.5 / 28$ & 14.5 & 14.5 & $\begin{array}{c}\text { VB, PPROM - cervical incompetence } 25.6 \\
690 / 2 \\
46, X Y \\
\text { Death at first day of life }\end{array}$ \\
\hline 6 & $13.5 / 42$ & 14.4, PPROM & - & $\begin{array}{c}\text { TOP, PPROM } \\
15.0 \\
\text { autopsy: PUV, cleft palate; } 47, \mathrm{XY},+18\end{array}$ \\
\hline 7 & $15.4 / 47$ & - & - & $\begin{array}{l}\text { VB } \\
\text { neonatal death due to prematurity } \\
\text { No follow up data }\end{array}$ \\
\hline
\end{tabular}

GA - gestational age; Cs — cesarean section; PROM — preterm rupture of membranes; MCMA — monochorionic monoamniotic; LUTO — lower urinary tract obstruction; CTG — cardiotocography; VB — vaginal birth; PPROM — premature preterm rupture of membranes; TOP — termination of pregnancy; PUV — posterior urethral valve

Table 2. Children born alive with LUTO after vesico-amniotic shunting — follow-up

\begin{tabular}{|c|c|c|c|c|}
\hline $\begin{array}{c}\text { Case } \\
\text { number }\end{array}$ & Urinary tract abnormalities & $\begin{array}{c}\text { Other organs } \\
\text { abnormalities }\end{array}$ & Interventions in the neonatal period & $\begin{array}{c}\text { Age (years)/serum } \\
\text { creatinine [mg\%] }\end{array}$ \\
\hline 1 & $\begin{array}{c}\text { PUVs } \\
\text { Bilateral vesicoureteral reflux } \\
\text { Right kidney hypoplastic }\end{array}$ & None & $\begin{array}{c}\text { Vesicostomy until resection of PUVs } \\
\text { PUVs resection }\end{array}$ & $6 / 0.57$ \\
\hline 2 & $\begin{array}{c}\text { Unilateral nephrostomy because of } \\
\text { vesico-ureteral reflux }\end{array}$ & $6 / 0.29$ \\
\hline 3 & Right kidney hypoplastic & $\begin{array}{c}\text { Anal atresia } \\
\text { Sacral agenesis }\end{array}$ & $\begin{array}{c}\text { Permanent vesicostomy } \\
\text { Permanent colostomy }\end{array}$ & $5 / 0.66$ \\
\hline
\end{tabular}

LUTO — lower urinary tract obstruction; PUVs — posterior urethral valves 
birth. We were unable to differentiate the cause of LUTO in Case no. 5 due to technical difficulties during necropsy and in Case no. 6 due to lack of follow up. However, the post-mortem evidence of mild left-sided hydrothorax in Case no. 5 suggested that also in this case LUTO was not an isolated defect.

All 4 neonates required surgical intervention after birth: PUV removal with ureterocutaneostomy due to vesicoureteral reflux (Case no. 1), vesicostomy (Cases no. 2, 3 and 4), colostomy (Cases 2 and 3 ) and gastrostomy (Case no. 4). The baby with additional intestinal problems (Case no. 4) died at the age of 1 month.

Three boys (Cases no. 1, 2 and 3) are alive, present with normal renal function at 6 years (case 1 and 2) and 5 years (case 3). Only one of them (Case no. 1) urinates freely, two other need vesicostomy and colostomy due to urethral and anal atresia and are awaiting repairing surgery in the future.

\section{DISCUSSION}

Prenatal interventions for LUTO is a widely debated problem. The rationale for in utero treatment is based on the possibility of removing the obstruction in the urethra and preventing renal damage as well as pulmonary hypoplasia by restoring the amniotic fluid volume. Generally, vesico-amniotic shunting is considered feasible in fetuses from singleton pregnancies $>16$ weeks presenting with isolated LUTO [7]. However, long-term results of second and third trimester urinary shunting for LUTO have been disappointing because the renal tissue in fetuses with severe LUTO seems to be damaged long before the intervention is usually performed. Nephrogenesis is mostly complete by the end of the first half of the pregnancy and in severe cases it is unlikely that urinary system decompression allows kidney regeneration. In contrast based on literature [8], long-term survival and morbidity of fetuses with mild forms of LUTO appears unchanged by fetal intervention.

On the other hand, yet published data on the outcomes of the early procedures are sparse. Only a few authors reported the results of early VAS performed before 16 weeks of gestation and its efficacy in improving the perinatal survival rate has not been proved. Usually, fetuses subjected to the early intervention were miscarried shortly thereafter or pregnancies were terminated due to later identification of additional malformations [9-11].

However, there are a few published case reports of children with LUTO that were subjected to early vesico-amniotic shunting and survived until birth with normal renal function what raises the question of the benefit of an earlier treatment [12-15].

The procedure of vesicoamniotic shunts is far from ideal as it has many disadvantages, like erroneous placement, displacement, urinary ascites formation and affecting blad- der function because presence of shunts preclude a normal urination cycle [16-18].

Despite those difficulties, due to technical reasons VAS seems to be the most feasible option for fetuses in the early pregnancy.

Another option of intervention in presumed LUTO is antegrade fetal cystoscopy. The main advantage of cystoscopy is that it potentially allows to perform the diagnosis of the type of the obstruction and provides physiological drainage of the urinary bladder. The procedure, similar to early VAS, does not require amnioinfusion, but is usually performed after 16 weeks of pregnancy [19].

Although the experience with this procedure is still limited, general neonatal outcomes of this procedure seem to be slighty better after cystoscopy then after VAS. Some authors found an improvement in survival at 6 months after either fetal intervention (cystoscopy and VAS) and a marginal advantage of fetal cystoscopy for renal function. Unfortunately, antegrade cystoscopy has also significant drawbacks. The time of the procedure is later in pregnancy, it is more difficult than early vesico-amniotic shunting, requires special equipment and may result in severe complications, like fetal death or development of urological fistulas [20].

Another vital issue which should be discussed is qualification for the procedure. This is a general problem of in-utero interventions in fetuses with LUTO, because some developmental malformations, like anal atresia, cannot be detected until late pregnancy, even despite fetal karyotyping and detailed ultrasonographic evaluation.

All our 7 procedures of early VAS were successful and only one pregnancy included in our series were terminated due to PPROM (in a fetus with trisomy 18). Also the procedure performed in a fetus from MCMA pregnancy was successful and uneventful (Case no. 3). Our observations confirm that the procedure of early VAS if technically feasible but has many disadvantages that limit its application. All our fetuses required repeated shunting due to the shunt displacement, a complication frequently reported in literature [7]. In our series of 17 cases of severe megacystis only as 3/6 fetuses treated with VAS survived after birth and still present with normal renal function at the age of 5-6 years. Unfortunately $2 / 3$ of them suffers from long term morbidity associated with urethral and anal atresia.

However, a question arises which is better: expectant approach at the expense of progressively deteriorating renal function [21], or early intervention with a high likelihood of normal renal function in the future. While the answer seems obvious from subjective parental perspective, also our objective findings seem to favour the early intervention since all survivors present with normal renal function at the age of 5-6 years. 
As this study was based on a small series of cases, its results does not allow us to formulate any definitive conclusions about the value of early vesico-amniotic shunting in fetuses with presumed LUTO. However, even taking into account all potential limitations, the results of this study suggest that early vesico-amniotic shunting can be considered on parental request in selected fetuses. Unfortunately, the results presented in this series reflect the limit of an earlier intervention, since it is not possible at this stage neither to determine the cause of LUTO nor to investigate precisely for associated anomalies. Although early intervention seems to prevent renal damage, the general prognosis in early severe LUTO is rather poor due to long-term morbidity and therefore conservative treatment or even pregnancy termination may be considered instead of any form of intrauterine intervention Taking into consideration the indisputable value of causative treatment which is relieving of the obstruction in fetal urethra and restoring the normal micturition in the fetal life in fetuses after early VAS other procedure like fetal cystoscopy or catheterization could be considered in later pregnancy, when it becomes technically possible [9, 10, 22, 23].

\section{REFERENCES}

1. Steinhardt G, Hogan W, Wood E, et al. Long-term survival in an infant with urethral atresia. J Urol. 1990; 143(2): 336-337, indexed in Pubmed: 2299725.

2. Quintero RA, Johnson MP, Romero R, et al. In-utero percutaneous cystoscopy in the management of fetal lower obstructive uropathy. Lancet. 1995; 346(8974): 537-540, indexed in Pubmed: 7658779.

3. Freedman $A L$, Johnson MP, Smith $C A$, et al. Long-term outcome in children after antenatal intervention for obstructive uropathies. Lancet. 1999; 354(9176): 374-377, doi: 10.1016/S0140-6736(98)11006-1, indexed in Pubmed: 10437866.

4. Parkhouse HF, Barratt TM, Dillon MJ, et al. Long-term outcome of boys with posterior urethral valves. Br J Urol. 1988; 62(1): 59-62, indexed in Pubmed: 3408870.

5. Robyr R, Benachi A, Daikha-Dahmane F, et al. Correlation between ultrasound and anatomical findings in fetuses with lower urinary tract obstruction in the first half of pregnancy. Ultrasound Obstet Gynecol. 2005; 25(5): 478-482, doi: 10.1002/uog.1878, indexed in Pubmed: 15816021.

6. Morris RK, Khan KS, Kilby MD. Vesicoamniotic shunting for fetal lower urinary tract obstruction: an overview. Arch Dis Child Fetal Neonatal Ed. 2007; 92(3): F166-F168, doi: 10.1136/adc.2006.099820, indexed in Pubmed: 17449853.

7. Morris RK, Malin GL, Quinlan-Jones E, et al. Percutaneous vesicoamniotic shunting in Lower Urinary Tract Obstruction (PLUTO) Collaborative Group. Percutaneous vesicoamniotic shunting versus conservative management for fetal lower urinary tract obstruction (PLUTO): a randomised trial. Lancet. 2013; 382(9903): 1496-1506, doi: 10.1016/S01406736(13)60992-7, indexed in Pubmed: 23953766.
8. Morris RK, Malin GL, Khan KS, et al. Systematic review of the effectiveness of antenatal intervention for the treatment of congenital lower urinary tract obstruction. BJOG. 2010; 117(4): 382-390, doi: 10.1111/j.1471-0528.2010.02500.x, indexed in Pubmed: 20374578.

9. Jouannic JM, Hyett JA, Pandya PP, et al. Perinatal outcome in fetuses with megacystis in the first half of pregnancy. Prenat Diagn. 2003; 23(4): 340-344, doi: 10.1002/pd.593, indexed in Pubmed: 12673643.

10. Favre R, Kohler M, Gasser B, et al. Early fetal megacystis between 11 and 15 weeks of gestation. Ultrasound Obstet Gynecol. 1999; 14(6): 402-406, doi: 10.1046/j.1469-0705.1999.14060402.x, indexed in Pubmed: 10658279.

11. Liao AW, Sebire NJ, Geerts L, et al. Megacystis at 10-14 weeks of gestation: chromosomal defects and outcome according to bladder length. Ultrasound Obstet Gynecol. 2003; 21(4): 338-341, doi: 10.1002/uog.81, indexed in Pubmed: 12704740.

12. Carroll SG, Soothill PW, Tizard J, et al. Vesicocentesis at 10-14 weeks of gestation for treatment of fetal megacystis. Ultrasound Obstet Gynecol. 2001; 18(4): 366-370, doi: 10.1046/j.0960-7692.2001.00531.x, indexed in Pubmed: 11778997.

13. Evans MI, Sacks AJ, Johnson MP, et al. Sequential invasive assessment of fetal renal function and the congenital hydronephrosis in utero. III. Early mid-timester urethral obstruction produces renal dysplasia. J Pediatr Surg. 1983; 18: 681-687.

14. Drugan A, Zador IE, Bhatia RK, et al. First trimester diagnosis and early in utero treatment of obstructive uropathy. Acta Obstet Gynecol Scand. 1989; 68(7): 645-649, indexed in Pubmed: 2698590.

15. Kim SK, Won HS, Shim JY, et al. Successful vesicoamniotic shunting of posterior urethral valves in the first trimester of pregnancy. Ultrasound Obstet Gynecol. 2005; 26(6): 666-668, doi: 10.1002/uog.2604, indexed in Pubmed: 16254891.

16. Sato $Y$, Kitagawa $H$, Pringle $K C$, et al. Effects of early vesicostomy in obstructive uropathy on bladder development. J Pediatr Surg. 2004; 39(12): 1849-1852, indexed in Pubmed: 15616948.

17. Kitagawa H, Pringle KC, Koike J, et al. Early bladder wall changes after creation of obstructive uropathy in the fetal lamb. Pediatr Surg Int. 2006; 22(11): 875-879, doi: 10.1007/s00383-006-1755-z, indexed in Pubmed: 16953456.

18. Nagae $H$, Kitagawa $H$, Pringle KC, et al. Pressure-limited vesico-amniotic shunt tube for fetal obstructive uropathy. J Pediatr Surg. 2006; 41(12): 20862089, doi: 10.1016/j.jpedsurg.2006.08.012, indexed in Pubmed: 17161212.

19. Ruano R, Sananes N, Sangi-Haghpeykar H, et al. Fetal intervention for severe lower urinary tract obstruction: a multicenter case-control study comparing fetal cystoscopy with vesicoamniotic shunting. Ultrasound Obstet Gynecol. 2015;45(4): 452-458, doi: 10.1002/uog.14652, indexed in Pubmed: 25157756.

20. Sananes N, Favre R, Koh CJ, et al. Urological fistulas after fetal cystoscopic laser ablation of posterior urethral valves: surgical technical aspects. UItrasound Obstet Gynecol. 2015; 45(2): 183-189, doi: 10.1002/uog.13405, indexed in Pubmed: 24817027.

21. Abdennadher W, Chalouhi G, Dreux S, et al. Fetal urine biochemistry at 13-23 weeks of gestation in lower urinary tract obstruction: criteria for in-utero treatment. Ultrasound Obstet Gynecol. 2015; 46(3): 306-311, doi: 10.1002/uog.14734, indexed in Pubmed: 25412852.

22. Ruano R, Yoshisaki CT, Salustiano EMA, et al. Early fetal cystoscopy for first-trimester severe megacystis. Ultrasound Obstet Gynecol. 2011; 37(6): 696-701, doi: 10.1002/uog.8963, indexed in Pubmed: 21337440.

23. Ruano R, Yoshizaki CT, Giron AM, et al. Cystoscopic placement of transurethral stent in a fetus with urethral stenosis. Ultrasound Obstet Gynecol. 2014; 44(2): 238-240, doi: 10.1002/uog.13293, indexed in Pubmed: 24375864 